\title{
Brain Expression of Presenilins in Sporadic and Early-onset, Familial Alzheimer's Disease
}

\author{
Paul M. Mathews, ${ }^{1}$ Anne M. Cataldo, ${ }^{1}$ Benjamin H. Kao, ${ }^{1}$ Anna G. Rudnicki, ${ }^{1}$ \\ Xi Qin, ${ }^{1}$ John L. Yang, ${ }^{1}$ Ying Jiang, ${ }^{1}$ Melanie Picciano, ${ }^{1}$ Christine Hulette, ${ }^{2}$ \\ Carol F. Lippa, ${ }^{3}$ Thomas D. Bird, ${ }^{4}$ David Nochlin, ${ }^{5}$ Jochen Walter, $^{6}$ \\ Christian Haass, ${ }^{6}$ Lyne Lévesque, ${ }^{7}$ Paul E. Fraser, ${ }^{7}$ Athena Andreadis, ${ }^{8}$ and \\ Ralph A. Nixon ${ }^{1}$ \\ ${ }^{1}$ Nathan Kline Institute, New York University School of Medicine, Orangeburg, \\ New York, U.S.A. \\ ${ }^{2}$ Kathleen Price Bryan Brain Bank, Bryan Alzheimer's Disease Research Center, \\ Duke University Medical Center, Durham, North Carolina, U.S.A. \\ ${ }^{3}$ Department of Neurology, Medical College of Pennsylvania, Philadelphia, \\ Pennsylvania, U.S.A. \\ ${ }^{4}$ Neurology and Medical Genetics, Veterans Administration Medical Center, Seattle, \\ Washington, U.S.A. \\ ${ }^{5}$ Department of Pathology, University Of Washington School of Medicine, Seattle, \\ Washington, U.S.A. \\ ${ }^{6}$ Department of Molecular Biology, Central Institute of Mental Health, Mannheim, Germany \\ ${ }^{7}$ Centre for Research in Neurodegenerative Disorders, University of Toronto, \\ Toronto, Ontario, Canada \\ ${ }^{8}$ Department of Neurology, Harvard Medical School, Department of Biomedical \\ Science, Eunice Kennedy Shriver Center, Waltham, Massachusetts, U.S.A. \\ Accepted June 30, 2000.
}

\begin{abstract}
Background: Mutations in the presenilin proteins cause early-onset, familial Alzheimer's disease (FAD). Materials and Methods: We characterized the cellular localization and endoproteolysis of presenilin 2 (PS2) and presenilin 1 (PS1) in brains from 25 individuals with presenilin-mutations causing FAD, as well as neurologically normal individuals and individuals with sporadic Alzheimer's disease (AD). Results: Amino-terminal antibodies to both presenilins predominantly decorated large neurons. Regional differences between the broad distributions of the two presenilins were greatest in the cerebellum, where most Purkinje cells showed high levels of only PS2 immunoreactivity. PS2 endoproteolysis in brain yielded multiple amino-terminal fragments similar in size to the PS1 amino-terminal fragments detected in brain. In addition, two different PS2 amino-terminal
\end{abstract}

antibodies also detected a prominent $42 \mathrm{kDa}$ band that may represent a novel PS2 form in human brain. Similar to PS1 findings, neither amino-terminal nor antiloop PS2 antibodies revealed substantial full-length PS2 in brain. Immunocytochemical examination of brains from individuals with the $\mathrm{N}_{141} \mathrm{I}$ PS2 mutation or eight different PS I mutations, spanning the molecule from the second transmembrane domain to the large cytoplasmic loop domain, revealed immunodecoration of no senile plaques and only neurofibrillary tangles in the $M_{139}$ I PS I mutation stained with PS I antibodies. Conclusions: Overall presenilin expression and the relative abundance of full-length and amino-terminal fragments in presenilin FAD cases were similar to control cases and sporadic AD cases. Thus, accumulation of full-length protein or other gross mismetabolism of neither PS2 nor PS 1 is a consequence of the FAD mutations examined. 


\section{Introduction}

Presenilin 1 (PS1) and presenilin 2 (PS2) are broadly distributed, multimembrane-spanning proteins identified because of their role in familial, early-onset Alzheimer's disease (FAD) (1-3). Immunolocalization studies have detected PSI predominantly within neurons (4-10), although some investigators also have reported extracellular labeling within plaques $(11,12)$. In transfected cells, presenilins are localized to the secretory pathway, predominantly the endoplasmic reticulum (ER) (13-16). This localization was confirmed by Lah and colleagues (6) for PSI at the electron microscopic level in neurons from monkey brain. More recent studies suggest that some PSI may be localized to more distal compartments in the secretory pathway, including the Golgi apparatus (17) and the plasma membrane (18). Little is currently known about the protein distribution of PS2 in normal human brain or in Alzheimer's disease (AD).

Both presenilins are synthesized as fulllength precursor proteins that are cleaved to yield amino- and carboxy-terminal fragments that accumulate within cells $(6,7,14,19-23)$. Multiple amino- and carboxy-terminal fragments of PS 1 accumulate in neuronal cell lines and in brain (24), and alternative cleavage sites in PS1 and PS2 appear to be used during neuronal differentiation (25). The hypothesis that PS I mutations exert their effects by altering the endoproteolytic processing of the protein has been suggested $(20,26)$, but not extensively examined in Alzheimer's disease $(12,27-29)$. To approach this question, we used immunocytochemistry and Western blot analysis to determine the relative distribution and expression of PS2 and PS 1 in individuals carrying eight different presenilin mutations, including mutations within the known cleavage domain, as well as mutations within other regions of the molecules. The distribution and endoproteolysis of PS2 in normal and pathological brain was also characterized for the first time. In brain, amino-terminal antibodies to both presenilins predominantly decorated neurons in an intracellular, ER-like pattern, and revealed broad, but not identical, regional distributions for the proteins. Like PS1, PS2 underwent processing in the brain that

Address correspondence and reprint requests to: Paul M. Mathews The Nathan Kline Institute, New York

University School of Medicine, 140 Old Orangeburg Road, Orangeburg, NY 10962, U.S.A. Phone: 914-398-5421;

Fax: 914-398-5422; E-mail: mathews@nki.rfmh.org yielded multiple amino-terminal fragments in the 28 to $34 \mathrm{kDa}$ range. Two amino-terminal PS2 antibodies also detected a larger species at $\sim 42 \mathrm{kDa}$ in human brain, which has been reported to be expressed following neuronal differentiation in culture (25). For both presenilins, differences in the relative distribution of full-length or amino-terminal fragments were small when FAD cases were compared with control or sporadic AD cases. Our data argue, therefore, that mutations of the presenilin genes that cause FAD are not associated with changes in the localization of PS2 or PS1, or with accumulation of the holoprotein and/or altered proportions of the amino-terminal fragments.

\section{Materials and Methods}

Transfected Cell Lines

The mouse fibroblast-like Ltk- cell (30), maintained in Dulbecco's modified Eagle's medium (DMEM) supplemented with $10 \%$ fetal bovine serum (FBS), penicillin, streptomycin, and glutamine, was transfected with human presenilin 1 (PS1) or presenilin 2 (PS2) cDNAs. The coding region of PS I was amplified by polymerase chain reaction (PCR) from a human liver cDNA library (Clontech, Palo Alto, CA) using the oligonucleotides 5'-TCACATCGGAAACAAAACAG and 5'-GCGAATTCGTCGACACCTCGTCCCTCAAATCT and introduced into the mammalian expression vector pcDNA3 (Invitrogen, Carlsbad, CA). The fidelity of the PCR was confirmed against the previously published sequence (2). The cDNA encoding human PS2 was generously provided by Drs. Jinhe Li and Huntington Potter (31) and also transferred to pcDNA3. Ltk- cells were transfected by lipid micelle (lipofectin, Gibco/BRL, Rockville, MD), and stable transfec-

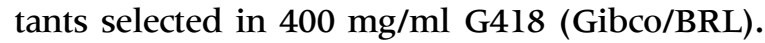
Treatment with sodium butyrate $(20 \mathrm{mM}$; Sigma, St. Louis, MO) for two days (30) was found to be necessary to detect presenilin expression. Multiple independent clones showing similar patterns of immunofluorescence labeling were identified. The lines used in this study were further subjected to limiting dilution subcloning.

\section{Human Tissue}

For immunocytochemistry studies, immersionfixed ( $10 \%$ phosphate buffered formalin) tissue blocks from the prefrontal cortex (Brodmann area 10), hippocampus, cerebellum, thalamus, and striatum were employed. Tissue from 12 in- 
dividuals (mean age $80 \pm 2.2$ years) with both clinical and neuropathological diagnoses of $\mathrm{AD}$ and 12 neurologically normal controls (mean age $72 \pm 2.4$ years) was examined. Biochemical analyses were performed using frozen brain tissue from the prefrontal cortex of 14 individuals similarly diagnosed with AD (mean age $76 \pm$ 3.8 years) and nine neurologically normal controls (mean age $69 \pm 4.2$ years). Post-mortem intervals between the two groups were closely matched $(\mathrm{AD}$ : mean $=8.6 \mathrm{hr}$, range $1.0-13.7 \mathrm{hr}$; control: mean $=9.5 \mathrm{hr}$, range $1.0-22.8 \mathrm{hr}$ ). In addition, frozen tissue from various brain regions was examined from two AD and two agematched control individuals as described in the "Results." The presence and magnitude of neurodegeneration and neurofibrillary changes were confirmed using Nissl and Bielschowsky histological stains and the neuropathological diagnosis of $\mathrm{AD}$ was established by (CERAD) criteria (32). Human brain tissue was procured from the Harvard Brain Tissue Resource Center at McLean Hospital (Belmont, MA) and the Neuropathology Core Facility of the Massachusetts Alzheimer's Disease Research Center (Massachusetts General Hospital, Boston, MA).

A total of 20 FAD cases with PS I mutations [ $\mathrm{M}_{139} \mathrm{I}$ ( 2 cases), $\mathrm{M}_{146} \mathrm{~L}, \mathrm{H}_{163} \mathrm{R}$ ( 2 cases), $\mathrm{G}_{209} \mathrm{~V}$, $\mathrm{A}_{246} \mathrm{Q}$ (7 cases), $\mathrm{A}_{260} \mathrm{~V}$ ( 2 cases), $\mathrm{L}_{286} \mathrm{~V}, \mathrm{C}_{410} \mathrm{Y}$ (4 cases)] were examined by immunocytochemistry. A subset of these, specified in the "Results," was also examined by Western blot analysis. An additional two PS 1 cases $\left(\mathrm{M}_{146} \mathrm{~L}\right.$ mutation) were examined only by Western blot analysis. Brains from three individuals with the $\mathrm{N}_{141} \mathrm{I}$ mutation in PS2 were also examined by immunocytochemistry and Western blot analysis.

\section{Antibodies}

A PCR-generated cDNA fragment encoding 47 amino acid residues of the amino-terminal region of PS1 (Fig. 1) was cloned into pGEX2T (Pharmacia, Piscataway, NJ) to yield a glutathione S-transferase fusion protein construct (GST-PSI/NT). After bacterial expression and purification, GST-PS1/ NT was used to immunize Balb/c mice. Hybridomas were generated by fusing spleen cells with Sp2/0-Ag 14 and initially screened by ELISA against GST-PSI/NT and also against three synthetic peptides (Fig. 1). Additional polyclonal PSI antibodies (PI antiserum) were raised against peptide $A$, which was immediately adjacent and aminoterminal to the NT1 binding site (Fig. 1).

PS2 antibodies were raised in rabbits against a similarly PCR-generated GST fusion protein containing 51 amino acids of the aminoterminal region of PS2 (GST-PS2/NT; Fig. 1). The resulting rabbit antiserum (NT14) was depleted of anti-GST antibodies by GST immunoaffinity chromatography, followed by affinity purification over GST-PS2/NT covalently coupled to glutathione agarose (33). A second antiserum raised against a GST fusion protein containing residues 1 through 80 of human PS2 and similarly affinity-purified, was used for confirmation of antibody specificity (25). The affinitypurified anti-loop PS2 polyclonal antibody was kindly provided by Drs. Gopal Thinakaran and Sangram (University of Chicago) and was previously described (23). AT-8, a monoclonal antibody directed against a phosphatase-sensitive epitope on paired helical filament tau, was provided by Dr. Marc Mercken (Janssen Research Foundation, Belgium) (34).

\section{GST-PS2/NT} ${ }_{22}$ SAESPTPRSCQ EGRQGPEDGE NTAQWRSQEN EEDGEEDPDR YVCSGVPGRP 72

\section{GST-PS1/NT \\ peptide $A$ peptide $B$ peptide $\mathrm{C}$}

Fig. 1. Fusion proteins and peptides used to generate and characterize antibodies. The amino acid sequences are given for the presenilin 2 (PS2) and presenilin 1 (PS1) regions included in the glutathione $S$-transferase (GST) fusion

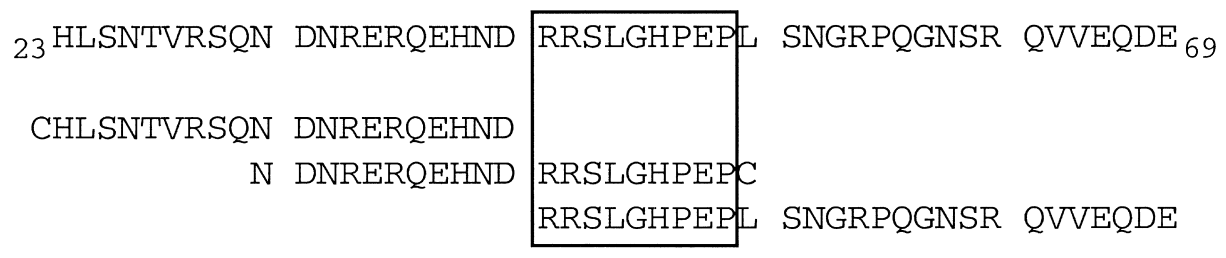

NT1

proteins used as antigens. The monoclonal antibody (NT1) (mAb) was characterized against peptides $A, B$ and $C$; its deduced binding site is boxed. The (Pl) antiserum was raised against peptide A. 


\section{Immunohistochemistry}

Formalin-fixed tissue blocks from the frontal pole, hippocampus, cerebellum, thalamus, and striatum of all brains were cut into $30-40 \mathrm{~mm}$ thick, free-floating vibratome sections. All tissue was pretreated by microwaving at full power (Tappan Speed Wave 1000 Agusta, GA) in water for $3 \mathrm{~min}$. Immunocytochemistry was performed using a modification of the avidinbiotin $(\mathrm{ABC})$ technique using standard Vectastain kits (Vector Laboratories, Burlingame, CA) with diaminobenzidine (DAB) as the chromogen (35). PSl immunostaining was performed using either NTl $(100 \mu \mathrm{g} / \mathrm{ml})$ or Pl (diluted 1:1000). PS2 immunostaining was performed using affinity-purified NT14 at $5 \mu \mathrm{g} / \mathrm{ml}$. NT14 immunostaining was found to be dependent on fixation time, with tissue fixed in formalin for $<3$ weeks labeling better than tissue fixed for longer periods. Antibody binding was at $4^{\circ} \mathrm{C}$ for $48-72 \mathrm{hr}$. Negative controls consisted of tissue sections incubated in the absence of primary antibody or in preimmune serum. Brain tissue used in double-labeling immunocytochemistry studies was initially stained for presenilin using the $\mathrm{ABC}$ method and $\mathrm{DAB}$ as the chromogen. Tissue was then washed in Tris-buffered saline (TBS, $15 \mathrm{mM}, \mathrm{pH}$ 7.4) followed by $10 \%$ dimethylformamide in TBS. Sections were immunostained again using (AT-8) at $2 \mu \mathrm{g} / \mathrm{ml}$ (34) and label was detected with Vector SG substrate (SG) as the chromogen (Vector Laboratories).

The immunoabsorption experiments were performed using a $5 \mathrm{X}$ molar excess of the indicated peptide or fusion protein to antibody. Peptide-antibody were complexed overnight at $4^{\circ} \mathrm{C}$ and immunocytochemistry preformed using the prebound absorbate as described above. Serial sections incubated in nonabsorbed antibodies served as controls. Additional controls were labeled with antibodies preabsorbed with irrelevant peptides.

\section{Protein Extraction and Western Blot Analysis}

$0.5 \mathrm{~g}$ of gray matter was homogenized in $250 \mathrm{mM}$ sucrose, $1 \mathrm{mM}$ EDTA, $1 \mathrm{mM}$ ethylene glycol-bis $(\beta$-aminoethyl ether $)-\mathbf{N}, \mathbf{N}, \mathbf{N}^{\prime}, \mathbf{N}^{\prime}-$ tetraacetic acid (EGTA), $20 \mathrm{mM}$ Tris (pH 7.4), and protease inhibitors [phenylmethylsulfonyl fluoride (PMSF), leupeptin, antipain, pepstatin], followed by centrifugation for $1 \mathrm{hr}$ at $100,000 \mathrm{X}$. The membrane pellet was extracted in $4.8 \%$ sodium dodecyl sulfate (SDS),
2 M urea, 8\% sucrose, and the DNA was sheared by passing through progressively smaller-diameter syringe needles prior to protein quantitation by Lowry assay (BioRad, Hercules, CA). PS1 and PS2 were fully recovered in the membrane fraction and not detected in the supernatant. Direct extraction of brain into $4.8 \%$ SDS, 2 M urea, $8 \%$ sucrose did not change the pattern of bands detected by Western blot analysis (data not shown). L cells grown on plastic were directly extracted in $4.8 \%$ SDS, $2 \mathrm{M}$ urea, $8 \%$ sucrose containing protease inhibitors, and DNA was sheared.

For Western blot analysis, samples containing equal amount of protein were heated to $56^{\circ} \mathrm{C}$ for $10 \mathrm{~min}$ in $4.8 \%$ SDS, $2 \mathrm{M}$ urea, $8 \%$ sucrose, $350 \mathrm{mM}$ 2-mercaptoethanol, and loaded onto discontinuous SDS-polyacrylamide gels. Including $2 \mathrm{M}$ urea in both the stacking and $10 \%$ acrylamide resolving gels improved resolution. Proteins were transferred to Immobilon-PPVDF membranes (Millipore, Boston, MA) and, after incubating overnight in binding solution [phosphate buffered saline (PBS), 5\% milk containing $5 \mu \mathrm{g} / \mathrm{ml}$ NTl or affinity-purified NT14], immunoreactivity was detected by incubating with horseradish peroxide (HRP)-coupled secondary antibody (Cappel, Durham, NC) followed by enhanced chemiluminescent protein (ECL; Amersham, Piscataway, NJ). For competition assays, peptides or fusion proteins were added to the binding solution (5:1 peptide/fusion protein: antibody molar ratio) and this mixture was pre-incubated overnight at $4^{\circ} \mathrm{C}$ prior to being used for Western blot analysis. Multiple exposures of the membrane to film were quantitated using the Scan Analysis software package (BioSoft, Palo Alto, CA).

\section{Results}

\section{Presenilin Antibodies}

We generated antibodies against the aminotermini of both PS2 and PS1. The resulting antibodies were extensively characterized by Western blot analysis using overexpression systems prior to being used to detect the endogenous presenilins expressed in human brain. The PS2 antiserum (NT14) was raised against a GST fusion protein containing 51 amino acids from the amino-terminal region of human PS2 (GST-PS2/NT) without homology to PS 1 (Fig. 1). Affinity-purified NT14 revealed bands in murine L/PS 1 and N2a cells 
of mobility greater than $\sim 60 \mathrm{kDa}$ and two smaller, minor bands that did not increase in intensity after overexpression of PS2 (Fig. 2A, compare lanes 1 and 3 with lanes 2 and 4). Importantly, NT14 did not detect proteins in extracts of L/PSI cells that would suggest any cross-reactivity with human PSI (Fig. 2A, lane 1). In L cells overexpressing the human PS2 (Fig. 2A, lane 2), NT14 specifically recognized a protein migrating at $\sim 45 \mathrm{kDa}$, a doublet at $\sim 32 / 30 \mathrm{kDa}$, and a lesser level of two proteins at $\sim 28 \mathrm{kDa}$. In the previously described N2a cells overexpressing human PS2 (Fig. 2A, lane 4) (23), NT14 detected a dramatic increase in the levels of an $\sim 55 \mathrm{kDa}$ protein and an $\sim 34$ kDa band (Fig. 2A, compare lane 4 with lane 3). This pattern in L/PS2 and N2a cells was consistent with PS2 being synthesized as a full-length protein that was proteolytically processed to yield amino- and carboxy-terminal fragments $(19,23)$. In extracts from human prefrontal cortex (Fig. 2A, lanes 5 and 6), NT14 strongly reacted with a $42 \mathrm{kDa}$ protein similar in mobility to an amino-terminal form of PS2
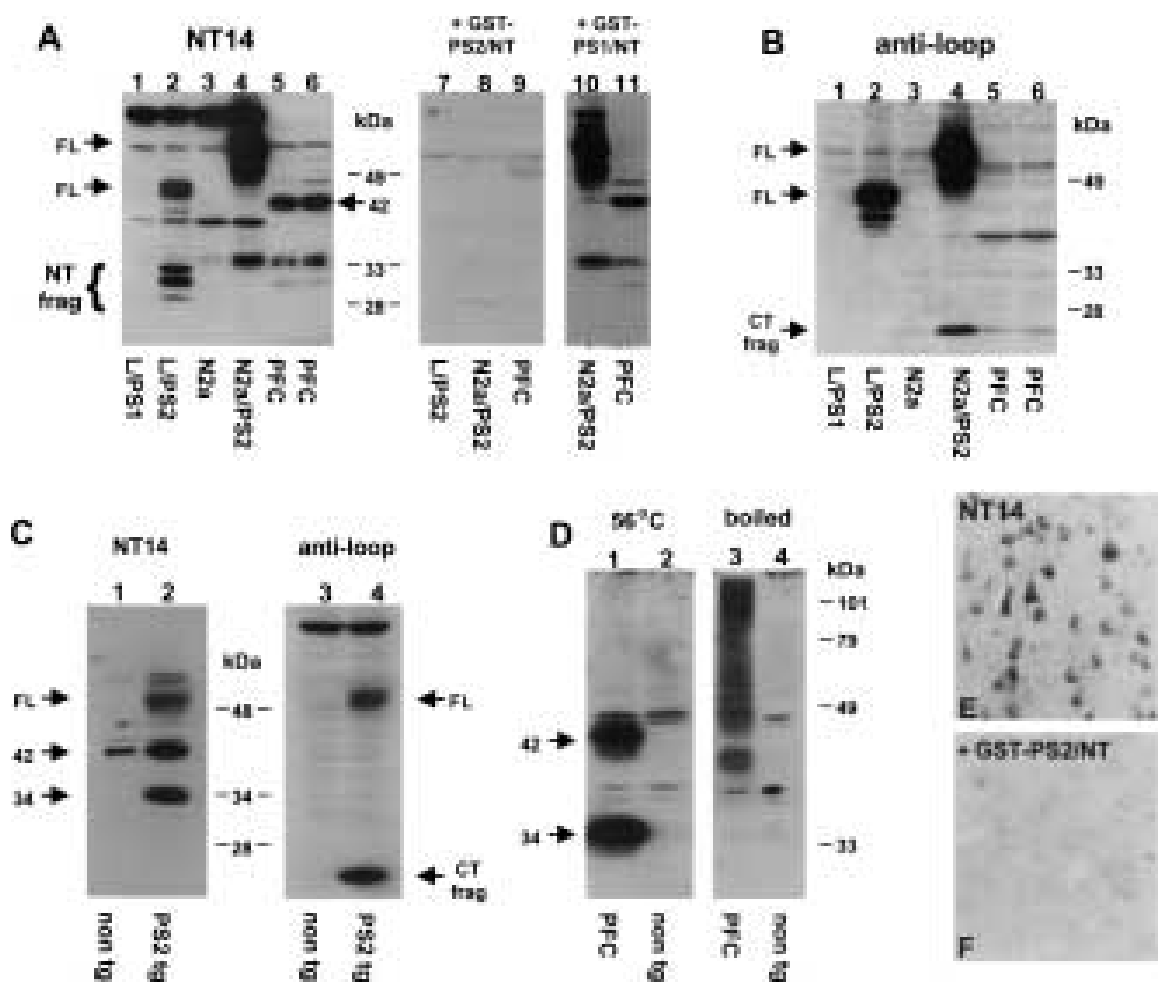

Fig. 2. Characterization of the anti-presenilin 2 (PS2) antiserum (NT14) by Western blot analysis. (A) Purified bacterially produced proteins or total cellular proteins were sized by SDS-PAGE, transferred to (PVDF) membrane, and probed with affinity-purified NT14. The following were loaded onto the gel: $50 \mu \mathrm{g}$ total protein extracted from (L/PS 1) cells (lane 1), (L/PS2) cells (lanes 2 and 7), mouse N2a neuroblastoma cells (lane 3), N2a cells overexpressing human PS2 (N2a/PS2, lanes 4, 8 and 10) (23), and $200 \mu \mathrm{g}$ of a membrane pellet prepared from the prefrontal cortex of two control individuals (lanes 5, 6, 9 and 11). The membrane containing lanes 7 and 9 was probed with NT14 binding solution containing glutathione S-transferase fusion protein construct (GST-PS2/NT); lanes 10 and 11, with NT14 binding solution contain GST-PS1/NT (see "Materials and Methods" and Fig. 1). (B) A membrane identical to that used in (A) was probed with an affinity-purified polyclonal antibody $(\mathrm{Ab})$ raised against the large loop domain of PS2 (23). (C) Mouse

brain homogenates were prepared from nontransgenic control (lanes 1 and 2) or human PS2 overexpressing transgenic (lanes 3 and 4) mice and analyzed by Western blot. $100 \mu \mathrm{g}$ of protein was loaded per lane. Lanes 1 and 2 were probed with affinity-purified NT14 and lanes 3 and 4 with the PS2 anti-loop Ab. (D) Total brain extract prepared from human prefrontal cortex (lanes 1 and 3) or a non-transgenic mouse (lanes 2 and 4) was either heated to $56^{\circ} \mathrm{C}$ (lanes 1 and 2) or placed in a boiling water bath (lanes 3 and 4) for $10 \mathrm{~min}$ prior to resolving on SDS-PAGE, transfer to membrane, and probing with NT14. (E and F) Specificity of PS2 detection in human brain. Serial sections from human prefrontal cortex were processed for immunohistochemistry as described in "Materials and Methods" and incubated with either NT14 (D) or NT14 in the presence of GST-PS2/NT (E). L/PS1, L cell expressing human PS 1; L/PS2, L cell expessing human PS2; N2a; Neuro-2a; PFC, prefrontal cortex; PS2 tg, PS2 transgenic; non tg, non-transgenic. 
specifically detected in differentiated neurons by Capell et al. (25). In brain, NT14 also detected a cluster of proteis at $\sim 34-30 \mathrm{kDa}$, corresponding in mobility to bands detected from L/PS2 and/or N2a/PS2 cells. Loading less protein (i.e. 50 or $100 \mu \mathrm{g} / \mathrm{lane})$ gave the same pattern of bands (data not shown). Addition of GST-PS2/NT to the binding solution eliminated immunoreactivity with the L/PS2 cell extract (Fig. 2A, lane 7), N2a/PS2 cell extract (Fig. 2A, lane 8), and a human brain extract (Fig. 2A, lane 9); whereas addition of GST-PS I/NT did not change the pattern detected (N2a/PS2, Fig. 2A, lane 10; human brain extract, Fig. 2A, lane 11).

To further demonstrate the specificity of NT14 for PS2 and to additionally characterize the bands seen in Figure 2A, a similar Western blot was probed with an affinity-purified polyclonal antibody raised against the large loop domain of PS2 (23). This antibody specifically detected the $\sim 45 \mathrm{kDa}$ band in L/PS2 cells seen with NT14 (Fig. 2C, lane 2), as well as the $\sim 55 \mathrm{kDa}$ seen in N2a/PS2 cells (Fig. 2C, lane 4), confirming that both antibodies recognized full-length PS2 in the transfected cells. In addition, anti-loop detected an $\sim 20$ kDa carboxyterminal PS2 fragment in the N2a cells (23) (Fig. 2C, lane 4). In prefrontal cortex (PFC; Fig. 2C, lanes 5 and 6), anti-loop revealed, although weakly, a similar $\sim 20 \mathrm{kDa}$ band, as well as a band at $\sim 38 \mathrm{kDa}$. The protein migrating at $\sim 42 \mathrm{kDa}$ in human PFC that strongly reacted with NT14 was not detected by the anti-loop antibody (compare Fig. 2A, lanes 5 and 6 with Fig. 2C, lanes 5 and 6), which we confirmed by reprobing membranes with the complementary antibody (data not shown). The failure of the amino-terminal NT14 and the anti-loop antibody to detect a common band in human PFC, in particular a band co-migrating with the fulllength protein that was seen following overexpression of PS2 in the cell lines and transgenic mice (Fig. 2C), suggested that little full-length PS2 accumulated within human brain. This has been shown for PS $1(20,22,23,36)$, and is consistent with PS2 accumulating in vivo as amino- and carboxy-terminal fragments (23). Additionally, these results argue that the $42 \mathrm{kDa}$ band detected by NT14 was not full-length or a nearly full-length, cytoplasmic-loop containing species of PS2.

The specificity of NT14 was further demonstrated by Western blot analysis of control and PS2 transgenic mouse brain (Fig. 2C) (37). NT14 showed weak immunoreactivity with an $\sim 42 \mathrm{kDa}$ protein in non-transgenic mouse brain (Fig. 2C, lane 1). In a PS2 transgenic mouse (Fig. 2C, lane 2), both full-length PS2 $(\sim 55 \mathrm{kDa})$ and an $\sim 34 \mathrm{kDa}$ amino-terminal fragment were detected, as was greater immunoreactivity with the $42 \mathrm{kDa}$ band. Probing these same extracts with the PS2 anti-loop antibody confirmed the identity of the fulllength PS2 in the transgenic mouse and revealed the $\sim 20 \mathrm{kDa}$ carboxy-terminal PS2 fragment (Fig. 2C, lane 4). To further substantiate that the $42 \mathrm{kDa}$ band detected by NT14 was likely to be an amino-terminal PS2 species, the migration on SDS-PAGE of extracts following denaturation at $56^{\circ} \mathrm{C}$ was compared with that of extracts heated in a boiling water bath for 10 min (Fig. 2D). Boiling of samples in SDSsample buffer has been reported to cause aggregation of presenilins (20). This treatment of human brain extracts resulted in the depletion of both the 42 and $34 \mathrm{kDa}$ bands and the appearance of a smear migrating at high molecular weight (compare Fig. 2D, lane 1 with lane 3). Minor bands detected by NT14 in an extract prepared from non-transgenic mouse brain were unchanged (compare Fig. 2D, lane 2 with lane 4). Finally, in human prefrontal cortex, NT14 strongly labeled large pyramidal neurons (Fig. 2E), labeling that was completely eliminated by preabsorbing NT14 with GST-PS2/NT (compare Figs. 2E and 2F).

Although these data strongly suggested that the $42 \mathrm{kDa}$ band detected by NTl 4 was a PS2 species, we performed similar Western blot analysis with a second amino-terminal PS2 antiserum (NT-PS2) (25) to confirm its identity. In Figure 3, the samples analyzed previously were probed with NT-PS2 (Fig. 3, lanes 1-5) and, for comparison, NT14 (Fig. 3, lanes 6-10). Both antibodies specifically detected full-length and amino-terminal fragments in the PS2 overexpressing L cells (Fig. 3, lanes 2 and 7) and N2a cells (Fig. 3, lanes 4 and 9). From human prefrontal cortex, NT-PS2 detected a $42 \mathrm{kDa}$ protein (Fig. 3, lane 5), as did NT14 (Fig. 3, lane 10). These bands were shown to co-migrate after the membranes were stripped and reprobed with the complementary antibody (data not shown). In addition to this $42 \mathrm{kDa}$ protein, NT-PS2 detected, although weakly, proteins migrating between $\sim 34$ and $28 \mathrm{kDa}$, identical to those seen by NT14 (compare Fig. 3, lanes 5 and 10). NT-PS2 also detected some larger molecular weight proteins not detected by NT14. Western blot analysis of PS2 expression in various human cell lines also 


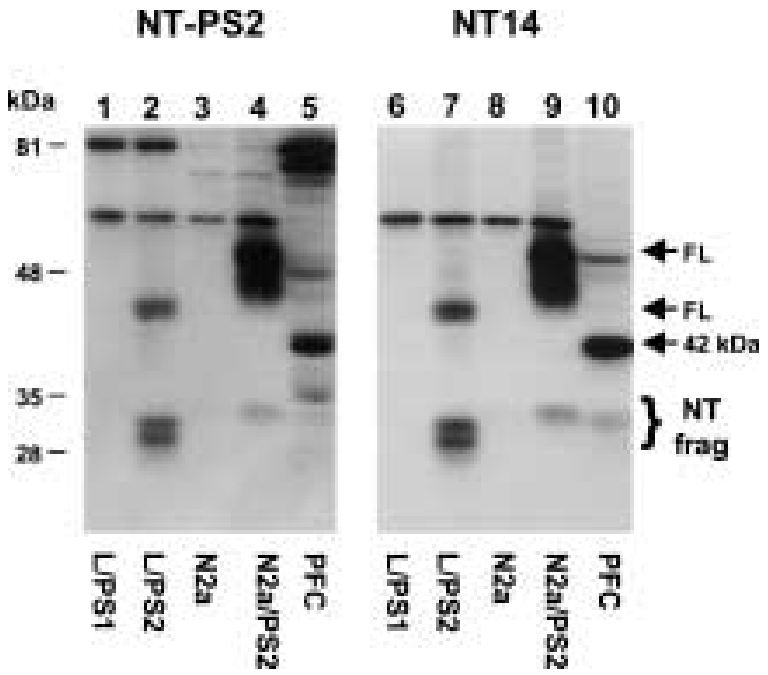

Fig. 3. Comparison of immunoreactivity patterns revealed by anti-PS2 antiserum (NT14) and a second amino-terminal PS2 anti-serum. A membrane identical to that used in Figure $2 \mathrm{~A}$ was probed with an affinity-purified amino-terminal presenilin 2 (PS2) anti-serum (NT-PS2) previously described by Capell et al. (25). A second membrane, probed with affinity-purified NT14, is shown for comparison. PFC, prefontal cortex; L/PS 1, L cell expressing human PS1; L/PS2, L cell expressing human PS2; N2a, Neuro-2a; N2a/PS2, N2a cell expressing human PS2; FL, full-length.

detected a $42 \mathrm{kDa}$ band in a human retinoblastoma line (Y79 cells; data not shown), but not in non-neuronal cell lines. These data using two well-characterized PS2 antibodies argue that the $42 \mathrm{kDa}$ band detected from human brain was an amino-terminal form of PS2, consistent with the observation by Capell and colleagues (25) of the expression in differentiated neuronal cultures of a similar $\sim 42 \mathrm{kDa}$ PS2 amino-terminal fragment. In conjunction with the specificity of NT14 shown using transfected cells and transgenic mice and the aggregation of the $42 \mathrm{kDa}$ brain signal following boiling, this strongly argues that most NT14 immunoreactivity within brain was with PS2 amino-terminal species migrating on SDS-PAGE at $\sim 42 \mathrm{kDa}$ and clustered at $\sim 34$ to $28 \mathrm{kDa}$.

A monoclonal antibody (NT1) $(25,38)$ raised against a GST fusion protein containing 47 amino acids from the amino-terminal region of human PS I (Fig. 1) recognized GST-PS 1/NT (Fig. 4A, lane 1), but not the GST carrier alone (Fig. 4A, lane 2) by Western blot analysis. Epitope mapping by ELISA with synthetic peptides (Fig. 1) indicated that NTl was

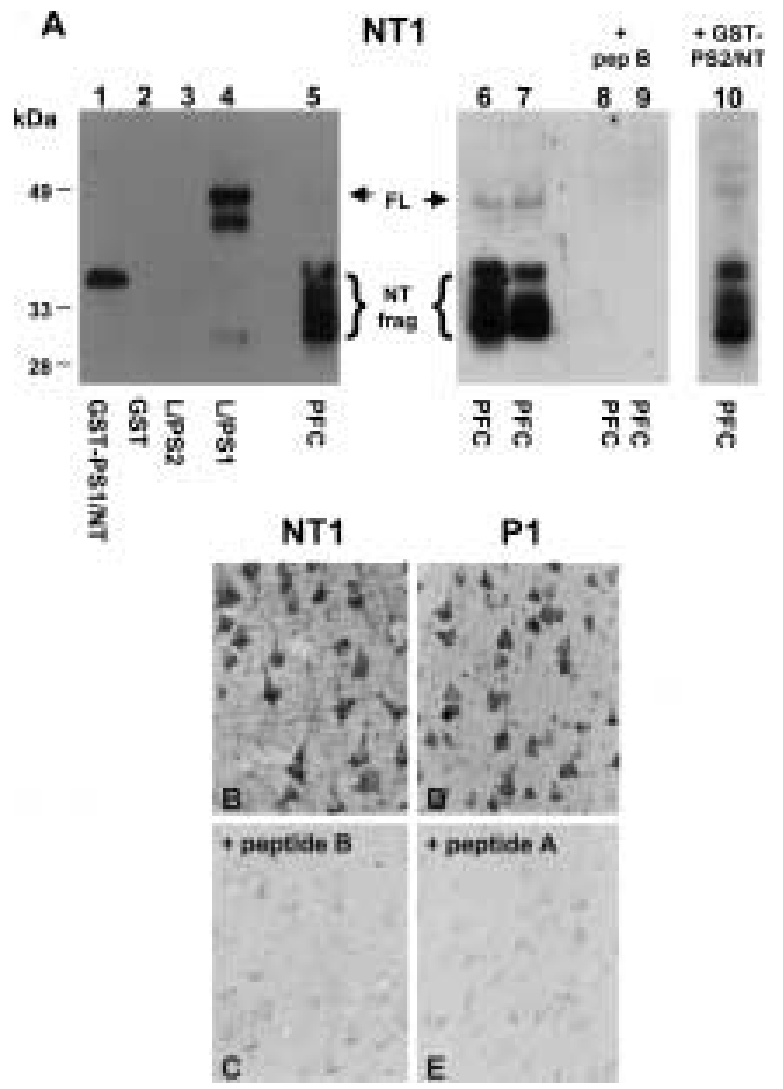

Fig. 4. Characterization of the anti-presenilin 1 (PS1) mAb (NT1) by Western blot analysis. (A) Proteins were prepared as in Figure 2 and probed with NTl. The following were loaded onto the gel: $2 \mathrm{ng}$ glutatheone S-transferase fusion protein contract (GST-PS1/NT; lane 1), 50 ng GST (lane 2), $50 \mu \mathrm{g}$ total protein extracted from murine L cells overexpressing human PS2 (L/PS2, lane 3) or human PSI (L/PS I, lane 4), and $200 \mu \mathrm{g}$ protein prepared from human prefrontal cortex (PFC) as described in "Materials and Methods" (lanes 5-10). Lanes 8 and 9 were probed with NTl in the presence of peptide B; lane 10, with the GST-PS2/NT fusion protein. Specificity of PS I detection in human brain. Serial $40 \mu \mathrm{m}$-vibratome sections from human prefrontal cortex were processed for immunocytochemistry as described in "Materials and Methods" and incubated with either NT1 (B) or NTl in the presence of peptide B (C). Similar serial sections were incubated in Pl (D) or Pl in the presence of peptide $C(E)$.

contained within the overlapping sequence RRSLGHPEP - a sequence that diverged from mouse PS I (RQRLDNPEP) and showed no homology to human PS2 (1-3,31). Accordingly, NT1 recognized full-length PS 1 , migrating at $\sim 46 \mathrm{kDa}$, and the $\sim 28 \mathrm{kDa}$ amino-terminal fragment produced by in vivo proteolysis (22) in L cells overexpressing PS I (L/PSI cell; Fig. 4A, lane 4), but not proteins in mouse $\mathrm{L}$ 
cells overexpressing human PS2 (L/PS2 cells; Fig. 4A, lane 3). Finally, NT1 recognized multiple bands migrating between $28 \mathrm{kDa}$ and $35 \mathrm{kDa}$ from human prefrontal cortex (Fig. 4A, lane 5). The identity of these bands was confirmed by including a synthetic peptide containing the NTl epitope in the binding solution (peptide B). Addition of the peptide eliminated NTl immunoreactivity with the 28 to $35 \mathrm{kDa}$ cluster of bands seen in human prefrontal cortex (compare Fig. 4A, lanes 6 and 7 with lanes 8 and 9). As expected given the epitope mapping of NT1, addition of the GST-PS2/NT fusion protein did not change the NTl pattern (Fig. 4A, lane 10). In human prefrontal cortex, NTl, like NT14, labeled large pyramidal neurons (Fig. 4). Most of this labeling was eliminated by preabsorbing the antibody with peptide B (compare Fig. 4B with 4C). Pl, a polyclonal antibody raised against a peptide (peptide A; Fig. 1) adjacent to the NTl binding site, yielded the same labeling pattern (Fig. 4D), which could be eliminated by preabsorbing the antibody with peptide A (Fig. 4E).

\section{Distribution of Presenilin Immunoreactivity in Neurons of Normal Human Brain}

Having carefully characterized our PS2 and PS 1 antibodies, we next determined the immunolocalization of PS2 in human brain, which had not been described previously, and examined PS2 expression in relationship to PS 1. PS2 and PSI were widely detected throughout cortical and subcortical areas, particularly within neuronal perikarya and proximal dendrites (Fig. 5). The neocortex and hippocampus were among the areas showing the greatest immunoreactivity. In the prefrontal cortex, PS2 and PSI immunoreactivity was particularly prominent in large pyramidal neurons of neocortical laminae II, III, and V (Figs. 5A, 5C, and 5E). Presenilin immunoreactivity was rarely detected in astrocytes, although occasional cells in the neuropil, identified as astrocytes, were minimally immunoreactive. Pyramidal neurons of the entorhinal cortex, corpus ammonu (CA) fields of the hippocampus, and granule cells of the dentate gyrus exhibited similar intensities of presenilin immunoreactivity in tissue from the same individual immunolabeled with either of the PSI antibodies (see for example Figs. 5E and 5F) or NT14.

Although PS2 and PS1 were similarly distributed in the prefrontal cortex, hippocampal

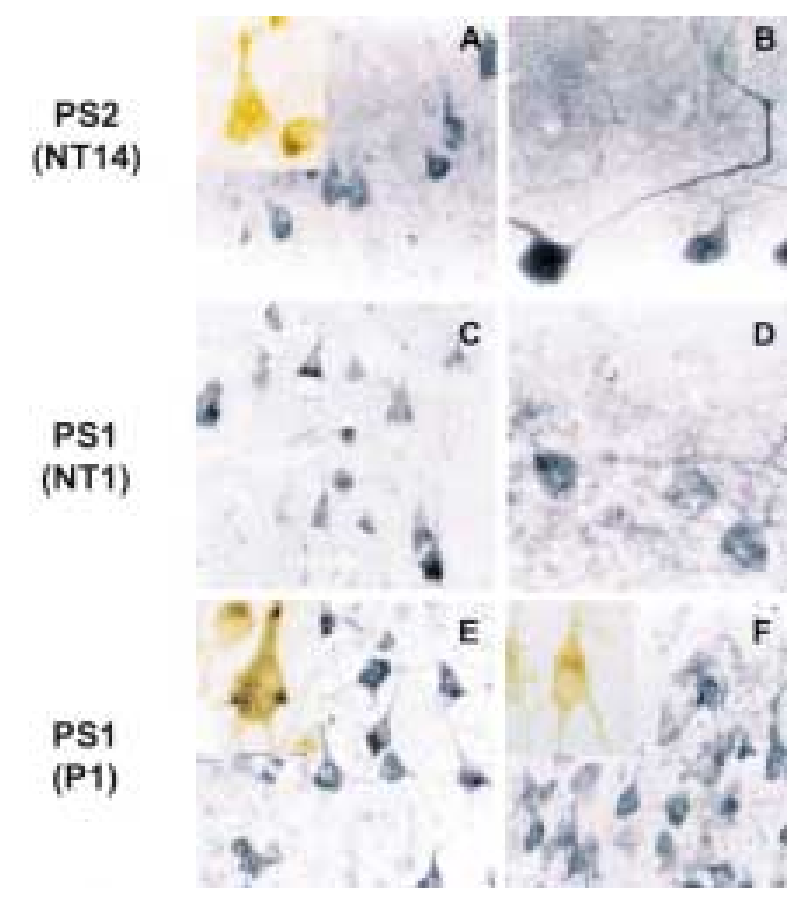

Fig. 5. Localization of presenilins in human control brain. Sections of the prefrontal cortex (A, $\mathrm{C}$, and E) and hippocampus (F) from neurologically normal controls immunostained with affinity-purified anti-PS2 anti serum (NT14; A) or with anti-PS 1 monoclonal antibody NT1 (C) or polyclonal antibody Pl (E, F) showed very uniform and consistent patterns of immunolabeling within the cell body and proximal dendrites of most neuronal pyramids. Levels of presenilin 2 (PS2) immunoreactivity in most Purkinje cells of the cerebellum were very high (B; affinity-purified NT14). In contrast to cortical neurons, levels of presenilin 1 (PS1) immunolabeling were low in Purkinje cells (D; NT1 labeling shown). Insets show higher magnification of the same brain regions using the same antibodies. Immunolabeling of sporadic Alzheimer's disease (AD) brain was similar. The tissue shown was stored in formalin approximately three months. PS I immunolabeling using either antibody was preserved upon much longer storage periods ( $>3$ years), although NT14 immunoreactivity declined.

formation, thalamus, and striatum, their relative expression was different in Purkinje cells. NT14 strongly labeled Purkinje cell bodies and their dendritic arborizations (Fig. 5B), the predominant sites of presenilin immunoreactivity in the cerebellum. Consistent with the immunocytochemical results, Western blot analysis with NT14 revealed greater immunoreactivity in the cerebellum, compared with other brain regions (data not shown). PSI immunoreactivity, detected by either NTI or P1, was comparatively low in Purkinje cells (Fig. 5D), as well as in thalamic neurons and in the large multipolar 
small round, and spindle-shaped neurons of the striatum. This finding was confirmed by Western blot analysis (data not shown).

\section{Presenilin Expression in Sporadic AD Brains}

The distribution and levels of PS2 and PS1 immunolabeling were similar between sporadic $\mathrm{AD}$ and control brains (not shown). With the exception of occasional pyramids that were more intensely stained and clearly atrophic, PS2 and PSI levels were not altered in neocortical pyramids of the at-risk regions of laminae III and $\mathrm{V}$ in sporadic AD brain. In addition, serial adjacent sections of the prefrontal cortex stained with Bielschowsky silver stain and separately probed

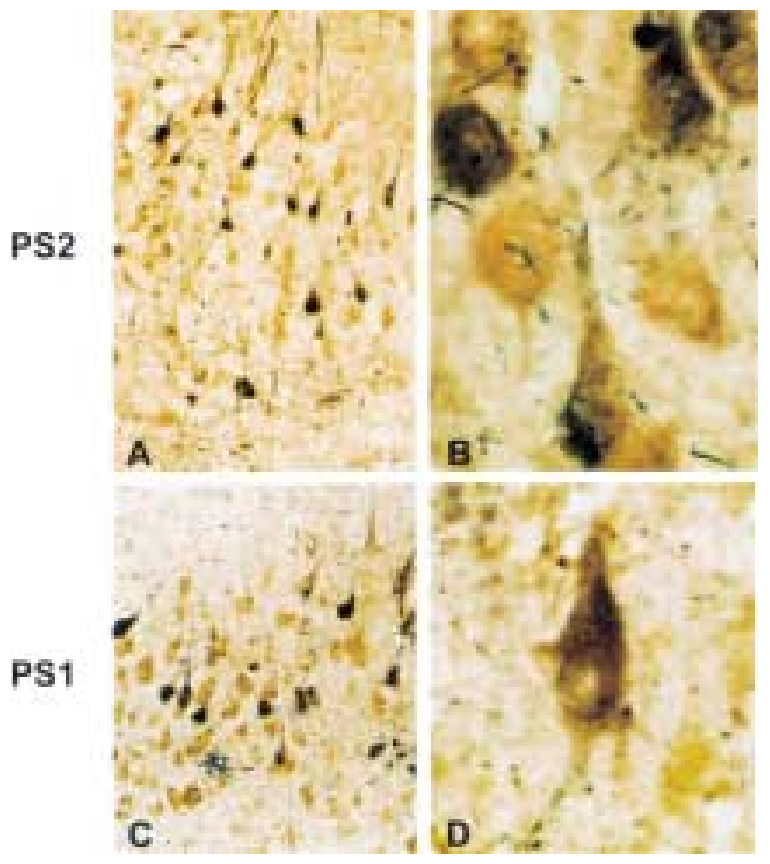

Fig. 6. Localization of presenilins within neurons containing neurofibrillary tangles in sporadic AD. Human Alzheimer's disease (AD) brain sections were double-labeled with antisera to presenilin 2 (PS2) or presenilin 1 (PS1) and paired helical filament tau (PHF-tau) by the avidin-biotin (ABC) technique and the two chromogens, diaminobenzidine (DAB) and Vectastain SG (SG) and visualized by brightfield microscopy. Labeling with affinity-purified anti-PS2 antiserum (NT14; A and $\mathrm{B}$ ) or (Pl; C and $\mathrm{D})$, both in brown, and the anti-PHF tau (AT-8), in blue (34), in neuronal pyramids of the entorhinal cortex (A and $\mathrm{B}$ ) and hippocampus (C and $D$ ) and from sporadic $A D$ brains demonstrate that a subpopulation of presenilinpositive neurons contain neurofibrillary pathology. The levels of presenilin immunolabeling in neurons containing neurofibrillary tangles, however, were similar to those in neurons not labeled by AT-8. with NT14, NT1, or P1, revealed no PS2 or PS 1 immunoreactivity within neuritic plaques.

Our amino-terminal presenilin antibodies did not immunolabel neurofibrillary tangles (NFT) in neuronal populations known to contain intracellular tangles by thioflavin $S$ staining and by anti-tau immunocytochemistry. In hippocampal sections of sporadic AD brains doublelabeled with antibodies to PS2 or PS1 and with the paired helical filament tau (PHF-tau) antibody AT-8 (Fig. 6), AT-8 positive neurons displayed the same intensity of presenilin immunolabeling as neurons that contained no neurofibrillary pathology. Moreover, presenilin and AT8 labeling did not closely colocalize.

In Figure 7, PS2 and PS1 expression and processing in prefrontal cortex from 14 indi-

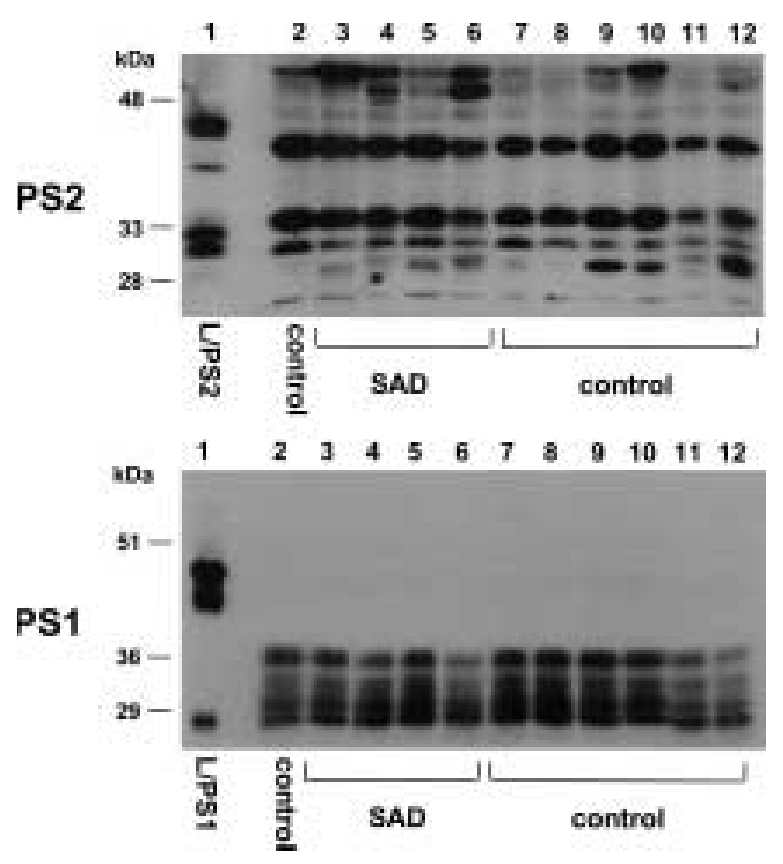

Fig. 7. Expression and processing of presenilins in control and sporadic Alzheimer's disease (AD) brain. Western blot analysis of PS2. Membrane pellets were prepared from human prefrontal cortex as described in "Materials and Methods" and proteins $(200 \mu \mathrm{g})$ separated by SDS-PAGE and transferred to membrane. Presenilin 2 (PS2) was detected using affinity-purified anti-PS2 antiserum (NT14). As a reference, $50 \mu \mathrm{g}$ of total protein from (L/PS2) cells was loaded in lane 1. Lanes 3 through 6 consist of material from individuals with the diagnosis of sporadic $\mathrm{AD}$; whereas, lanes 2 and 7 through 12 are from age-matched controls. (Bottom panel) Western blot analysis of PS 1 from human brain. A similarly prepared membrane was probed with (NT1). Lane 1 was loaded with $50 \mu \mathrm{g}$ of total protein from (L/PS1) cells. L/PS2, L cell expressing human PS2; L/PS1, L cell expressing human PS 1 ; SAD, sporadic AD. 
viduals diagnosed with sporadic AD (four cases depicted in Fig. 7, lanes 3-6) were compared with that from nine age-matched, neurologically normal controls (six cases shown in Fig. 7, lanes 2, 7-12) by Western blot analysis. Although PS2 expression and banding patterns were somewhat heterogeneous among cases, differences appeared to be unrelated to disease status or post-mortem interval (Fig. 7, top panel). Prominent 42 and $34 \mathrm{kDa}$ bands, and a weaker band at $30 \mathrm{kDa}$, were consistently detected along with variable amounts of the $28 \mathrm{kDa}$ band. Higher molecular weight bands (migrating between approximately 50 and $60 \mathrm{kDa}$ ), were also variable and may have corresponded to the aggregated PS2 described by Kim et al. (19). PSI expression and type of processing were remarkably similar among individuals within each group and between the $\mathrm{AD}$ and control groups (Fig. 7, bottom panel). Quantitation of the total PSI immunoreactivity from control vs. AD cases confirmed this interpretation [control: $1.00 \pm 0.04 ; \mathrm{AD}$ : $0.91 \pm 0.05$; $p \geqslant 0.1$; expressed as mean \pm standard error (SE), normalized to control value].

\section{Presenilin Expression in Familial AD Brains}

Immunocytochemical examination of brain tissue from 20 individuals with mutations in PS 1 and from three individuals with the $\mathrm{N}_{141} \mathrm{I}$ PS2 mutation showed PSI immunolabeling to be similar in intensity. Cellular and regional distribution were similar to that seen in either control or sporadic AD cases for all of the PS 1 mutations examined $\left(\mathrm{M}_{146} \mathrm{~L}, \mathrm{H}_{163} \mathrm{R}, \mathrm{G}_{209} \mathrm{~V}\right.$, $\mathrm{A}_{246} \mathrm{Q}, \mathrm{A}_{260} \mathrm{~V}, \mathrm{C}_{410} \mathrm{Y}, \mathrm{A}_{260} \mathrm{~V}$ ) and the $\mathrm{N}_{141} \mathrm{I}$ PS2 mutation, with the single exception of the PS 1 $\mathrm{M}_{139} \mathrm{I}$ mutation. In the two $\mathrm{M}_{139} \mathrm{I}$ cases examined, both amino-terminal PSI antibodies detected neurofibrillary tangles in $15-20 \%$ of the neocortical pyramids (Fig. 8). Unfortunately, none of the FAD tissue labeled with the NT14 antiserum, presumably due to relatively long storage in fixative. We found that storing either control or sporadic AD tissue in formalin for more than 3 weeks eliminated NT14 immunoreactivity.

Figure 9 shows the comparison of PS 1 and PS2 expression by Western blot analysis of control cases (Fig. 9, lanes 1-3) and sporadic AD cases (Fig. 9, lanes 4 and 5) with six PS 1 FAD cases (Fig. 9, lanes 6-11) and three PS2 FAD cases (Fig. 9, lanes 12-14). PS2 expression was found to be similar among these individuals (Fig. 9, top panel). In all cases, NTl4 re-

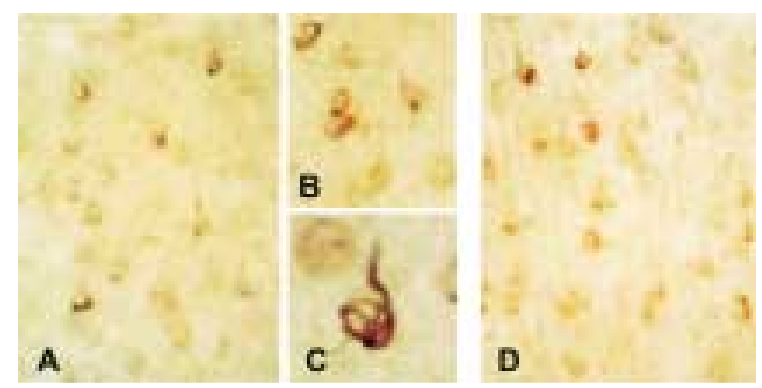

Fig. 8. Presenilin antibodies detect neurofibrillary tangles in neurons of familial Alzheimer's disease (AD) brains. A significant number of neocortical neurons from lamina III of familial Alzheimer's disease (FAD) brains carrying the mutation $\mathrm{M}_{139} \mathrm{I}$ in presenilin 1 (PS 1 ; A, B, C are from one case, D from a second) showed intracellular neurofibrillary tangle-like labeling with PS 1 antibodies (labeling with (P1) is shown; a similar pattern was seen with NT1). Similar labeling was not detected in the same populations from control (see Fig. 5), sporadic AD (see Fig. 6), or other FAD brains (not shown).

vealed a strong 42 and $34 \mathrm{kDa}$ band, as well as a weaker band at $30 \mathrm{kDa}$. As seen with control and sporadic AD cases, substantial variability was seen in the intensity of the $28 \mathrm{kDa}$ band, as well as in the bands detected above $55 \mathrm{kDa}$,

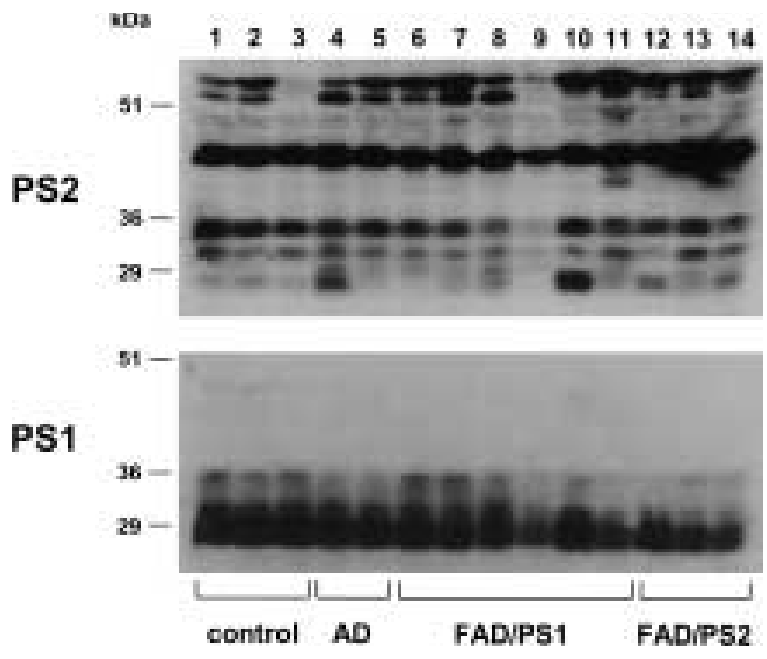

Fig. 9. Western blot analysis of presenilin 1 (PS1) and presenilin 2 (PS2) expression in familial Alzheimer's disease (FAD) cases. $200 \mu \mathrm{g}$ of protein prepared from prefrontal cortex from control cases (lanes 1-3), sporadic AD cases (lanes 4 and 5), FAD cases caused by mutations within PS 1 (lanes 6 and 7: $M_{139} \mathrm{I}$; lanes 8 and 9: $\mathrm{H}_{163} \mathrm{R}$; lane 10: $\mathrm{G}_{209} \mathrm{~V}$; lane 11: $\mathrm{A}_{260} \mathrm{~V}$ ), and FAD cases caused by the $\mathrm{N}_{141} \mathrm{I}$ mutation within PS2 (lanes 12-14) were analyzed by Western blot as in Figure 7. An addition six PS I FAD cases $\left(M_{146} I\right.$, two cases; and $\mathrm{A}_{246} \mathrm{E}$, four cases) were analyzed with similar results. 
although this variation did not correlate with any group. Levels of PSI expression and the distribution of amino-terminal forms detected by NTl were similar among these four groups (Fig. 9, bottom panel), although two of the six PS 1 FAD cases (Fig. 9, lanes 9 and 11 ) and the three PS2 FAD cases (Fig. 9, lanes 12-14) had somewhat reduced levels of PSI expression relative to the other cases, particularly of the more slowly migrating processed forms. The $46 \mathrm{kDa}$ full-length PSI was not found to be more abundant in the FAD cases. The uniformity of sample loading was confirmed by Ponceau S staining of membranes, as well as by probing with an antibody against the $\alpha$-subunit of the $\mathrm{Na}$, K-ATPase (data not shown).

\section{Discussion}

In this study, we have examined the expression, localization, and processing of both PS2 and PSI in human brain. We found both proteins to be broadly distributed throughout human brain by Western blot analysis and immunocytochemistry on fixed tissue. In all brain areas, neurons immunolabeled strongly; glia exhibited very weak to negligible immunoreactivity. Moreover, large pyramidal neurons and Purkinje cells consistently showed greater presenilin immunolabeling than did smaller neurons. We did, however, detect regional differences in the brain pattern of presenilin expression when directly comparing these proteins in the same individuals. Both proteins were detected in pyramidal neurons of the neocortex and hippocampus at relatively high levels. In Purkinje cells, however, PS2 was enriched relative to PSI, which was less abundant in cerebellum than in other brain regions. Extensive $\beta$-amyloid burden within the cerebellum has been reported in PS1linked FAD cases, consistent with relatively high levels of presenilin expression in the cerebellum leading, in these cases, to more extensive cerebellar pathology than is seen in sporadic AD $(39,40)$.

In vivo proteolytic processing of PSI to yield amino- and carboxy-terminal fragments has been shown in various systems, including mouse brain (22), monkey brain (6), and human brain $(12,27)$. Consistent with the data we presented here, it was the proteolytic fragments of PS I that accumulated in human brain and the holoprotein was barely detectable. Endoprote- olysis of PS2 also has been described for cells in culture $(23,25)$. Our data support the idea that, like PS1, proteolytic fragments of PS2 accumulate in brain. The complexity of the aminoterminal forms of both PS1 and PS2 that we describe in brain agrees with recent reports of unique proteolytic processing of these proteins during neuronal differentiation in culture $(24,25)$.

In sporadic AD brain, the intensity of PS 1 and PS2 immunolabeling, as well as the distributions of immunoreactive neurons, are identical to those seen in control brain. In addition, our immunocytochemical analysis did not detect either PS1 or PS2 in senile plaques. Some previous reports have shown PSI immunoreactivity in plaques (11), although not all of these antibodies detected processed forms of PS 1 by Western blot analysis $(5,10)$. Our results, however, are consistent with results obtained by others using amino-terminal PS 1 antibodies that detect PS 1 fragments $(4,6,7)$.

In addition, we did not find a correlation between presenilin immunoreactivity and the presence of neurofibrillary tangles in sporadic AD. AT-8, an early marker for PHF-tau formation (34), was found to react with a subset of presenilin-positive pyramidal neurons in atrisk regions of the cortex and hippocampus. Although our study was not designed to be quantitative, the intensity of presenilin immunolabeling in neurons containing PHF-tau was found to be similar to PHF-tau negative neurons and neurons of control brain, suggesting that gross changes in presenilin levels do not accompany early cytoskeletal pathology. This is in contrast to the finding of Giannakopoulos et al. (11), who used a quantitative approach to show increased PS 1 immunoreactivity with an anti-loop antibody in those neurons not showing neurofibrillary tangles in $\mathrm{AD}$ brain. A number of factors could account for this difference, including differences in the region of the PSI molecule recognized by the various antibodies. Additionally, we did not detect neurofibrillary tangles in sporadic AD with our amino-terminal presenilin antibodies. Busciglio and colleagues (4) reported similar results with their PS 1 amino-terminal antibody. A PSI carboxy-terminal antibody, however, did label neurofibrillary tangles in $\mathrm{AD}$ brain, indicating that the amino- and carboxy-terminal fragments of PS I localize differently and may play different roles during AD pathology. 
Of the eight different PS I FAD mutations and single PS2 FAD mutation we examined, none showed labeling of plaques with PS 1 antibodies. Pyramidal neurons from both individuals carrying the $M_{139} \mathrm{I}$ PS I mutation uniquely showed neurofibrillary tangle labeling with PS 1 antibodies. The expression and processing of PS 1 in the $\mathrm{M}_{139}$ I cases was similar to control or sporadic $A D$, indicating that a failure in endoproteolysis does not account for the unusual distribution of PSI in the $M_{139} I$ mutations. It is possible that the $\mathrm{M}_{139} \mathrm{I}$ leads to a mislocalization of the amino-terminus of PS 1 during neurodegeneration.

We did not detect changes in PS1 or PS2 expression or proteolysis by Western blot analysis of prefrontal cortex in control and sporadic $A D$. This suggests that large changes in the metabolism of PS1 or PS2 are not associated with $A D$ pathogenesis in sporadic disease. The hypothesis has been suggested that PS I mutations may affect the metabolism of the protein. The clustering of FAD-causing amino acid substitutions near the proteolytic processing site (28) suggests that a deficiency in endoproteolysis may be a common finding in PS 1 mutations, and the PSI exon 9 deletion mutation interferes with endoproteolysis (22). This is further supported by reports of differences in proteolysis when mutant PS 1 is overexpressed in cell lines $(20,26)$ and for the $\mathrm{G}_{209} \mathrm{~V}$ PS $1 \mathrm{mu}-$ tation in human brain (12), as well as by the insensitivity of the PS2 $\mathrm{N}_{141} \mathrm{I}$ mutation to cleavage by caspase-3 (26). Endoproteolysis of PS 1 carrying missense mutations, however, has been reported in cultured cells $(28,37,41)$ and in transgenic mice $(37,41-43)$, although the ratio of the full-length protein to processed forms in these systems varies. We did not detect substantial differences in the pattern of PSI amino-terminal fragments or the accumulation of full-length PSI in three mutations within the large loop domain $\left(\mathrm{G}_{209} \mathrm{~V}, \mathrm{~A}_{246} \mathrm{E}\right.$, and $\left.\mathrm{A}_{260} \mathrm{~V}\right)$ near the cleavage site(s) or in three amino-terminal mutations $\left(\mathrm{M}_{139} \mathrm{I}, \mathrm{M}_{146} \mathrm{I}\right.$, and $\left.\mathrm{H}_{163} \mathrm{R}\right)$. In addition, the $\mathrm{N}_{141} \mathrm{I}$ mutation did not appear to affect the accumulation of proteolytically processed PS2. In agreement with Hendricks and colleagues (27), who examined PS 1 expression in individuals with the $\mathrm{I}_{143} \mathrm{~T}$ and $\mathrm{G}_{384}$ A substitutions, this indicates that presenilin mutations do not necessarily result in accumulation of full-length protein in vivo and suggests caution when interpreting overexpression systems, where full-length, wild-type
PS1 and PS2 accumulate to a much greater extent than when expressed at endogenous levels. However, FAD-causing mutations may affect endoproteolysis without causing accumulation of full-length protein: both PS2 and PSI are degraded by the proteasome when overexpressed (19,44-48). Robust turn-over of full-length, mutant protein would prevent its accumulation in neurons and would be consistent with our Western blot data from FAD brain.

\section{Acknowledgments}

This work was supported by a LEAD (leadership and Excellence in Alzheimer Disease) grant from the NIA (R. N. and A. C.; AG10916) and a NRSA fellowship (P. M.; NS09848). Human brain tissue was provided in part by the Harvard Brain Tissue Resource Center, which is supported in part by the PHS grant number MH/NS 31862 and the Kathleen Price Bryan Brain Bank at Duke University Medical Center. We wish to thank Drs. Gopal Thinakaran and Sangram Sisodia for providing us with the N2a cell extracts and the anti-loop PS2 polyclonal antibody.

\section{References}

1. Levy-Lahad E, Wasco W, Poorkaj P, et al. (1995) Candidate gene for the chromosome 1 familial Alzheimer's disease locus. Science 269: 973-977.

2. Sherrington R, Rogaev EI, Liang Y, et al. (1995) Cloning of a gene bearing missense mutations in early-onset familial Alzheimer's disease. Nature 375: $754-760$.

3. Rogaev EI, Sherrington R, Rogaeva EA, et al. (1995) Familial Alzheimer's disease in kindreds with missense mutations in a gene on chromosome 1 related to the Alzheimer's disease type 3 gene. Nature 376: 775-778.

4. Busciglio J, Hartmann $\mathrm{H}$, Lorenzo $\mathrm{A}$, et al. (1997) Neuronal localization of presenilin-1 and association with amyloid plaques and neurofibrillary tangles in Alzheimer's disease. J. Neurosci. 17: 5101-5107.

5. Elder GA, Tezapsidis N, Carter J, et al. (1996) Identification and neuron specific expression of the S182/presenilin I protein in human and rodent brains. J. Neurosci. Res. 45: 308-320.

6. Lah JJ, Heilman CJ, Nash NR, et al. (1997) Light and electron microscopic localization of presenilin-1 in primate brain. J. Neurosci. 17: 1971-1980. 
7. Lee MK, Slunt HH, Martin LJ, et al. (1996) Expression of presenilin 1 and 2 (PS 1 and PS2) in human and murine tissues. J. Neurosci. 16: 7513-7525.

8. Moussaoui S, Czech C, Pradier L, et al. (1996) Immunohistochemical analysis of presenilin-1 expression in the mouse brain. FEBS Lett. 383: 219-222.

9. Murphy GM, Forno LS, Ellis WG, et al. (1996) Antibodies to presenilin proteins detect neurofibrillary tangles in Alzheimer's disease. Am. J. Pathol. 149: 1839-1846.

10. Weber LL, Leissring MA, Yang AJ, Glabe CG, Cribbs DH, LaFerla FM. (1997) Presenilin-1 immunoreactivity is localized intracellularly in Alzheimer's disease brain, but not detected in amyloid plaques. Exp. Neurol. 143: 37-44.

11. Giannakopoulos P, Bouras C, Kovari E, et al. (1997) Presenilin-1-immunoreactive neurons are preserved in late-onset Alzheimer's disease. Am. J. Pathol. 150: 429-436.

12. Levey AI, Heilman CJ, Lah JJ, et al. (1997) Presenilin-1 protein expression in familial and sporadic Alzheimer's disease. Ann. Neurol. 41: 742-753.

13. Cook DG, Sung JC, Golde TE, et al. (1996) Expression and analysis of presenilin 1 in a human neuronal system: localization in cell bodies and dendrites. Proc. Natl. Acad. Sci. U.S.A. 93: 9223-9228.

14. De Strooper B, Beullens M, Contreras B, et al. (1997) Phosphorylation, subcellular localization, and membrane orientation of the Alzheimer's disease-associated presenilins. $J$. Biol. Chem. 272: 3590-3598.

15. Doan A, Thinakaran G, Borchelt DR, et al. (1996) Protein topology of presenilin 1. Neuron 17: 1023-1030.

16. Kovacs DM, Fausett HJ, Page KJ, et al. (1996) Alzheimer-associated presenilins 1 and 2: neuronal expression in brain and localization to intracellular membranes in mammalian cells. Nat. Med. 2: 224-229.

17. Zhang J, Kang DE, Xia W, et al. (1998) Subcellular distribution and turnover of presenilins in transfected cells. J. Biol. Chem. 273: 12436-12442.

18. De Strooper B, Annaert W, Cupers P, et al. (1999) A presenilin-1-dependent $\gamma$-secretase-like protease mediates release of Notch intracellular domain. Nature 398: 518-522.

19. Kim TW, Pettingell WH, Hallmark OG, Moir RD, Wasco W, Tanzi RE. (1997) Endoproteolytic cleavage and proteasomal degradation of presenilin 2 in transfected cells. J. Biol. Chem. 272: 11006-11010.

20. Mercken M, Takahashi H, Honda T, et al. (1996) Characterization of human presenilin 1 using $\mathrm{N}$ terminal specific monoclonal antibodies: evidence that Alzheimer mutations affect proteolytic processing. FEBS Lett. 389: 297-303.

21. Seeger M, Nordstedt C, Petanceska S, et al.
(1997) Evidence for phosphorylation and oligomeric assembly of presenilin 1. Proc. Natl. Acad. Sci. U.S.A. 94: 5090-5094.

22. Thinakaran G, Borchelt DR, Lee MK, et al. (1996) Endoproteolysis of presenilin 1 and accumulation of processed derivatives in vivo. $\mathrm{Neu}$ ron 17: 181-190.

23. Thinakaran G, Harris CL, Ratovitski T, et al. (1997) Evidence that levels of presenilins (PS I and PS2) are coordinately regulated by competition for limiting cellular factors. J. Biol. Chem. 272: 28415-28422.

24. Hartmann H, Busciglio J, Baumann KH, Staufenbiel M, Yankner BA. (1997) Developmental regulation of presenilin-1 processing in the brain suggests a role in neuronal differentiation. J. Biol. Chem. 272: 14505-14508.

25. Capell A, Saffrich R, Olivo JC, et al. (1997) Cellular expression and proteolytic processing of presenilin proteins is developmentally regulated during neuronal differentiation. J. Neurochem. 69: 2432-2440.

26. Kim TW, Pettingell WH, Jung YK, Kovacs DM, Tanzi RE. (1997) Alternative cleavage of Alzheimer-associated presenilins during apoptosis by a caspase-3 family protease. Science 277: 373-376.

27. Hendriks L, Thinakaran G, Harris CL, et al. (1997) Processing of presenilin 1 in brains of patients with Alzheimer's disease and controls. Neuroreport 8: 1717-1721.

28. Podlisny MB, Citron M, Amarante $P$, et al. (1997) Presenilin proteins undergo heterogeneous endoproteolysis between Thr291 and Ala299 and occur as stable $\mathrm{N}$ - and $\mathrm{C}$-terminal fragments in normal and Alzheimer brain tissue. Neurobiol. Dis. 3: 325-337.

29. Okochi M, Ishii K, Usami M, et al. (1997) Proteolytic processing of presenilin-1 (PS-1) is not associated with Alzheimer's disease with or without PS-1 mutations. FEBS Lett. 418: 162-166.

30. Mathews PM, Martinie JB, Fambrough DM. (1992) The pathway and targeting signal for delivery of the integral membrane glycoprotein LEP100 to lysosomes. J. Cell Biol. 118: 1027-1040.

31. Li J, Ma J, Potter H. (1995) Identification and expression analysis of a potential familial Alzheimer disease gene on chromosome 1 related to $\mathrm{AD} 3$. Proc. Natl. Acad. Sci. U.S.A. 92: 12180-12184.

32. Mirra SS, Heyman A, McKeel D, et al. (1991) The consortium to establish a registry for Alzheimer's disease (CERAD). Part II. Standardization of the neuropathologic assessment of Alzheimer's disease. Neurology 41: 479-486.

33. Koff A, Giordano A, Desai D, et al. (1992) Formation and activation of a cyclin E-cdk2 complex during the Gl phase of the human cell cycle. Science 257: 1689-1694.

34. Mercken M, Vandermeeren M, Lubke U, et al. 
(1992) Monoclonal antibodies with selective specificity for Alzheimer Tau are directed against phosphatase-sensitive epitopes. Acta Neuropathol. 84: 265-272.

35. Cataldo AM, Nixon RA. (1990) Enzymatically active lysosomal proteases are associated with amyloid deposits in Alzheimer brain. Proc. Natl. Acad. Sci. U.S.A. 87: 3861-3865.

36. Ratovitski T, Slunt HH, Thinakaran G, Price DL, Sisodia SS, Borchelt DR. (1997) Endoproteolytic processing and stabilization of wild-type and mutant presenilin. J. Biol. Chem. 272: 24536-24541.

37. Citron M, Westaway D, Xia W, et al. (1997) Mutant presenilins of Alzheimer's disease increase production of 42 - residue amyloid $\beta$-protein in both transfected cells and transgenic mice. Nat. Med. 3: 67-72.

38. Levesque L, Annaert W, Craessaerts K, et al. (1999) Developmental expression of wild-type and mutant presenilin-1 in hippocampal neurons from transgenic mice: evidence for novel species-specific properties of human presenilin1. Mol. Med. 8: 542-554.

39. Wisniewski T, Dowjat WK, Buxbaum JD, et al. (1998) A novel Polish presenilin-1 mutation (P117L) is associated with familial Alzheimer's disease and leads to death as early as the age of 28 years. Neuroreport 9: 217-221.

40. Lemere CA, Blusztajn JK, Yamaguchi H, Wisniewski T, Saido TC, Selkoe DJ. (1996) Sequence of deposition of heterogeneous amyloid $\beta$-peptides and APO E in Down syndrome: im- plications for initial events in amyloid plaque formation. Neurobiol. Dis. 3: 16-32.

41. Borchelt DR, Thinakaran G, Eckman CB, et al. (1996) Familial Alzheimer's disease-linked presenilin 1 variants elevate $\mathrm{A} \beta 1-42 / 1-40$ ratio in vitro and in vivo. Neuron 17: 1005-1013.

42. Duff K, Eckman C, Zehr C, et al. (1996) Increased amyloid- $\beta 42(43)$ in brains of mice expressing mutant presenilin 1. Nature 383: 710-713.

43. Lee MK, Borchelt DR, Kim G, et al. (1997) Hyperaccumulation of FAD-linked presenilin 1 variants in vivo. Nat. Med. 3: 756-760.

44. Marambaud P, Alves da Costa C, Ancolio K, Checler F. (1998) Alzheimer's disease-linked mutation of presenilin 2 (N141I-PS2) drastically lowers APP $\alpha$ secretion: control by the proteasome. Biochem. Biophys. Res. Commun. 252: 134-138.

45. Marambaud P, Ancolio K, Lopez-Perez E, Checler F. (1998) Proteasome inhibitors prevent the degradation of familial Alzheimer's diseaselinked presenilin 1 and potentiate $\mathrm{A} \beta 42$ recovery from human cells. Mol. Med. 4: 147-157.

46. Honda T, Yasutake $\mathrm{K}$, Nihonmatsu N, et al. (1999) Dual roles of proteasome in the metabolism of presenilin 1. J. Neurochem. 72: 255-261.

47. Steiner H, Capell A, Haass C. (1999) Proteolytic processing and degradation of Alzheimer's disease relevant proteins. Biochem. Soc. Trans. 27: 234-242.

48. Fraser PE, Levesque G, Yu G, et al. (1998) Presenilin 1 is actively degraded by the $26 \mathrm{~S}$ proteasome. Neurobiol. Aging 19: S19-S21. 